\title{
Fear of the future: a response to Dr. José Eizayaga
}

\section{Marcelo Candegabe}

\author{
Universidad Candegabe de Homeopatía (Distance Learning University), \\ Buenos Aires, Argentina
}

Dear Editor,

I was truly surprised last month when I read in International Journal of High Dilution Research the article "REDIMEH Project: Integrative Ibero-American Network for Clinical Research in Homeopathy" by Dr. José Eizayaga, Maimonides University, in Argentina [1].

In this work, my colleague wanted to present a brand new pilot project to fight what he sees as the great failure of homeopathy: "The lack of high quality clinical research, which could bring about positive changes in daily practice and bring real progress in therapeutic efficacy".

Beyond the opinion that each physician may have about this diagnosis about the scene of the legacy of Samuel Hahnemann's work, I really believe that everyone should celebrate any initiative that seeks to expand our knowledge.

However, Eizayaga's paper only devotes few paragraphs to talk about REDIMEH and instead, spends more than two pages criticizing HUMA method, a work I conducted for many years with colleagues and that has recently gained importance and aroused curiosity and interest, leading to a modest rise in popularity.

By request from my peers and colleagues, I am obliged to respond to Dr. Eizayaga in this short letter. To avoid cumbersome statements, I will try to be brief and concise, but I won't accept further discussion with someone who does not seem to be moved by respect and genuine interest about others' work, but maybe by other intentions that I do not understand.

I want to make clear that it is painful for me to review his text, because he does not hesitate to make offensive suggestions against my person, my work and my teammates. I have high respect for and a loving remembrance of his father, with whom I discussed on several occasions, in which always respect prevailed as well as the desire for a better homeopathy. I am even more upset by his son's words as he represents a wellknown center such as Maimonides University in Argentina.

What can motivate an attack as the way to present a project as auspicious as REDIMEH? I think I know what's behind. Perhaps it is the fear of the future, this feeling so human that pervades us all when we deal with something we do not know but we suspect that something may change in our future.

Dr. Eizayaga qualifies HUMA method as anti-scientific and as the fruit of false theorizing that should fall together with the exhibitions of "quacks and impostors." My colleague argues that there are "quasi-guru claims of new fancy methodologies that could sound attractive to many practitioners". HUMA is an example of such despicable practices he aims to study "in detail, to show its propositions, internal logic, rationale and plausibility".

As first premise, he quotes: "There must be something beyond life, the vital force, disease and symptoms, and this something is ... the number". This is an incorrect assumption. I have never stated this assertion, which may be attractive or not, but it is not part of my methodology of practice. In none of the theoretical arguments 
of the method that I described this concept appears and I'm surprised that it was mentioned as the first premise of HUMA Method. I find it striking that the very first point of Dr. Eizayaga is a misstep. This shortcoming may be attributed to the fact that he didn't contacted me or my fellow researchers, at least as far as I know, to familiarize himself with the ideas and principles that govern this methodology.

Judging from the sources cited in his article, my colleague had only access to the material available to everyone in the website of the distance-learning university that I lead (www.universidadcandegabe.org) and where I discuss some of my ideas and concerns. Clearly, if the concern of this paper was constructive criticism, it would have been intellectually honest to become more acquainted with it before.

A similar flaw occurs when Dr. Eizayaga accuses me of not having explicitly mentioned Pythagoras in my work, suggesting that he concealed the influence of the Father of Mathematics by "a mystic sect around these ideas number". Here Dr Eizayaga is also wrong because everybody acknowledges, even the most modern research in mathematics and physics, the weight of the philosophy of Pythagoras, called by him "an ingenious and sophisticated response to the much more primitive Greek idea on earth, fire, water and air".

Like all the palpable influence of Hellenic culture today, philosophers who see themselves as "Platonic" or "Aristotelian," for example, are those who adhere to one or the other fundamental ideas, but clearly do not believe, for example, in the existence of Plato's ideas or Aristotle's geocentric universe. To think that we should reject a mathematical theorem stating that in a right triangle the square of the hypotenuse equals the sum of the squares of the two legs or the existence of irrational numbers simply because their finished formulations were made by Pythagoras and his disciples, who believed in metempsychosis, demonstrates a misunderstanding of the way it is inherited and accepted knowledge is inherited and accepted by scientific disciplines.

Throughout the text, one can't help but noting the desire of Dr. Eizayaga to seek the approval of science for every instance of homeopathy. I agree with him in the need for this discipline to seek high and competitive standards, which will improve it daily. However, we also need to understand the development of the activity of scientists and their wisdom as temporary social constructions. What the scientific community states as true and valid today is very different to what was considered so fifty years ago. It is also very different from the ideas that were fashionable in many fields a century ago, just to mention near time periods.

It is naive to think that there is something like a Supreme Court lead by the sciences that can judge what is true from what it is not with complete accuracy and impartiality. One of the foundations of scientific knowledge is its tentativeness. Nothing in science is written on stone, but everything is open to be criticized and improved. This is by no means a flaw or a weakness of science, but simply a feature of its nature.

Dr. Eizayaga also tries to get scientific approval for HUMA method - of which, again, he seems to know nothing more than loose references from texts published on the website of University Candegabe - adding that "numbers and mathematics are a human invention and convention, and only exist in human thoughts".

I wonder, first, if science and its dictates are not also an "invention and a human convention" and what could be wrong with that. On the other hand, I find it striking that the author is unaware of a long discussion about the origin of mathematics. This is a debate that goes back several centuries and still lacks a clear winner. The question is whether mathematics is created or discovered. There are good arguments for both positions, but since quantum physics arose the latter position made new adherents and reasons, thanks to the insights that chaos and order have not been well understood. This issue has been discussed in major works by authors such as Heisenberg, Tohm, Wilberg, Mandelbrot, Briggs, Peat, Prigogine, Bohm, Wasensberg, Davies and Green, among others. 
This intellectual battle is central to the field of mathematics and has interesting corollaries. The absence of any mention of it in Dr. Eizayaga's text is at least unexpected and can be a sign of simple oversight, misunderstanding of the subject or deliberate concealment of an essential element in this discussion.

Dr. Eizayaga also ascribes to HUMA method the discovery of "a strange attribute" and a "hidden mystery" in the names of homeopathic remedies written in Latin. Again, the assertion has no reliable source as far as I know and perhaps all his criticism can be due to a wrong reconstruction of a complex system that he does not know.

Therefore, I'd like to take a little time to explain, in the brevity imposed by this answer, why I do believe that it is interesting to analyze the names of remedies. These names are written in Latin, a language that has a mathematical basis and is used as substrate of information by the International Phonetic Alphabet (a system of phonetic notation devised by linguists to agree on a standardized, practical accurate objects to represent the sounds of any spoken language); this could be used as a new model to analyze each remedy and compare it to objective data from the patient when subjected to the same analytical approach.

Dr. Eizayaga pejoratively states that "after long studies, devoted scientists discovered a mathematical formula which can reduce the Latin name of medicines into a number!" In fact, the investigation looks for a key contained in the phonetic code number that relates the numeric phonetic properties of the substance and some objective patient data. For its construction we used a statistical distribution methodology to arrive at a probability calculation as accurate as possible.

The intertwining of the information contained in the variables studied - symmetrical distribution curve and Gaussian curves skewed distributions, Gumbel, Pearson, for example - shows that not all remedies have the same number of symptoms keeping constant the values of the patient's data.

Dr. Eizayaga can agree or disagree with these intuitions guiding our research, but he cannot simplistically reduce them to a few statements before having internalized their fundamentals

Later on, he even talks about "the devoted scientists" wondering "who are these scientists? And where is their work?" Let me name just a few of the many professionals who worked in the main team led by me. Among the physicians, Horacio Monsalvo, who was kind enough to take for months all the records in my office with the classic method of "Pure Homeopathy" so that we could checked them through HUMA method; Alberta Cumaldi, Eduardo Bitis and Gustavo Cataldi, who is a doctor and has a degree in philosophy, among others.

Others who also put their determination and effort in this research are Andrea Brancalion - an Italian homeopathic veterinarian, who is the supervisor of the veterinary module of HUMA method - and his colleagues, Graciela Berrastro and Veronica Cavalcabúe.

Along with them, working in mathematics were Victoria Paternostro, the computer statisticians Luis Enrique Grau and Mary Yantorno, the philosopher and Latinist Ida Deschamps, the philosopher Diego Vila and the mathematics professor Raúl Fernández Calvo, who taught me for more than a decade quantum physics and who I will always remember as a the responsible for "awakening" my ideas.

They are really my partners in this journey, who were encouraged to put their effort and dedication to what was and remains a work guided by the love for homeopathy and the desire to bring to patients and physicians more accurate tools for achieving health.

I have to mention, also, the enlightening encounter with the German quantum physicist Hans-Peter Dürr, Director of the Max-Planck-Institute of Physics and professor of physics at the Ludwig Maximilian University. 
On the occasion of the 60th Congress of LMHI held in Berlin in 2005, when I was invited as a speaker, I could hear Professor Dürr's words at the inaugural conference. I got then the chance to talk to him about some of my concerns about both homeopathy and quantum physics. I told him that we should seek new horizons and new models for understanding reality that would necessarily locate us beyond physical frameworks and closer to the metaphysical ones, if we wished to avoid blind alleys.

These ideas made Mr. Dürr stop his activities that day and stay all afternoon talking with me in the presence of the German obstetrician Otrud Lindemann, who performed the translation, and doctors Hugo Carrara, from the Homeopathic Academy of Venice and Leoncio Padrón, director of Folk Medicine in Cuba.

The suggestions and ideas that we had in that meeting were the beginning of what is now the HUMA method. It was him who warned me on the lack of progress in research if we were to continue with a structured thought based solely on rationalism and the pressing need to extend our observations to other levels of understanding.

"In my humble opinion, there should be many codes that relate medicines to patients," said Dürr. I proposed to investigate other analog models, looking for the most stable parameters that could also be the most objective parameters, ones which could be as far from human subjectivity as possible.

With these ideas I came back from Berlin and began to sort through these ideas and others that I have been simmering for years arising from my medical practice, which is more than 28 years long, and the readings and conducts studies always driven by the desire to increase my training, something I learned from my father and my teachers.

All the professionals I have mentioned above were brave enough to join me in this intellectual adventure, which had and still has its obstacles. However, the awesome possibilities for the future neither overwhelm nor paralyze us, but encourage us to take on the challenge of achieving full health for each patient.

Like all my colleagues around the world, I know that the treatment scheme in classic homeopathy is currently disturbed by the encroachment of modern complexity and multiplicity, increasingly incomprehensible new symptoms and remedies found in investigations. And even with all these developments, there are still millions of materials Leith to experiment.

The HUMA method of investigation begins by a new parameter to reveal the information contained in patterns of individuality. It is a new approach to a mathematical paradigm for homeopathy, which proposes a phonetic code number as the new parameter. While taking into account the requirements of individuality and completeness, similarity is now achieved according to a key contained in the phonetic code number that relates the numeric phonetic properties of the Latin name of the substance and the key contained in the phonetic code numerical data regarding the patient's individuality and goals.

The code is not a "dark secret" designed to deal with an "implausible free association of ideas full of logical pitfalls and with no connection at all with simple reality" as mentioned by Dr. Eizayaga. It is, actually, a numerical series arising from phonetic-numeric codes from the Latin name of the various remedies consistent with the numerical series of data from the patient taken to the Latin language and its subsequent phoneticnumeric code. Nothing more than that: there is no "implausible free association of ideas", but simply a finding of comparability of data.

Considering the words of Nobel Prize winner Eugene Wigner: "The miracle of the relationship between language, mathematics and the formulation of the laws of physics is a wonderful gift that we do not understand nor deserve. We should be grateful for it and expect it to remain valid in future research and extending, for better or for worse, for pleasure or even to our dismay, to other branches of knowledge". 
I sincerely regret that my colleague put such harsh adjectives to a serious and extensive research as this. There is nothing here that is dark or mysterious. He cannot deny the possibility of the existence of new methodologies, neither can he explain with his rational look what the "vital force" described by Hahnemann is, "information" underlying the fifth force which has not yet been described by scientists of our time yet but this not means that is not true just because haven't been explained.

A real rational study, within the parameters Dr. Eizayaga claims, cannot establish "what homeopathic remedies contain", what is the basis for the "revitalization of substances" or "what the mechanism of action of homeopathy is". What can Dr. Eizayaga do about it?

Once again we face the only reason for the durability of Homeopathy along time: the state of health often reached, the cases cured by the method devised by Hahnemann relating substances to patients, the success of those who project and pursue their dreams thanks to cure their ailments.

The new model of similarity proposed by HUMA method claims to be judged by its effects, not through speculation or intellectual misconceptions.

The formula that contains the method and its HUMA algorithm will not be disclosed for the entire duration of investigation precisely to preserve the originality of the idea and protect it from interferences, damage or methodological deviations.

Eizayaga also warns in its report that the presentation of clinical cases treated with HUMA method is informal. I find this strange since I remember seeing him in some of my presentations where I showed cases of patients with clinical analysis on the evolution of each case. In none of these opportunities he questioned me on the cases described. Did he have questions then? Why did he chose not to ask them to me personally? Why did he prefer to ask from a distance?

The result of the algorithmic computation, moreover, is not a single remedy appearing "magically" in the vast widening of the medical field but a ranked list of remedies that best correspond to the study of individual cases and among which the homeopath must choose the most similar to the patient as homeopathic doctrine postulates.

Finally, Dr. Eizayaga points out in his review "let us mention the most delicate problem here. Homeopathy practitioners can easily buy the calculations through Internet, getting an important discount if acquired in dozens"... After so many rants and complaints against the method, is this the most delicate problem? He wonders "Could we imagine Hahnemann asking doctors to send him a check with the symptoms list of their patients and getting back from him the name of the remedy to be prescribed or the remedy itself with its name masked?" Sadly, I understand that with this statement Dr. Eizayaga wants to place me as "seller of illusions" and suggests that behind my efforts there is only a desire for money.

Maybe I should only believe that I am witnessing, once again, the findings arising from ignorance of the item he want to analyze. I prefer to believe that and leave out my fears that so many errors and carelessness in these veiled accusations are motivated by something else.

I can only answer briefly to this point by explaining that the studies are done online as the database is extended periodically with new remedies and applications, making it impossible to have another system. The money, moreover, is reinvested in Universidad Candegabe de Homeopatía (Distance Learning University) for continuing research, academic activities and scholarships for many professionals who cannot afford the costs of the courses as well as to the support of the institution.

At present, there are over a hundred users HUMA method in twenty countries and has proven to be extraordinarily effective by doctors. I even found an unexpected event in the application of this methodology 
in veterinary. The marketing department of the University has made arrangements so that any physician can have access to the use of the algorithm.

It is striking, on the other hand, the fact that Dr. Eizayaga raises this criticism about Money, when he was representative for Argentina for selling his father's works, Dr. Francisco X. Eizayaga, one of the most prominent Argentinian homeopaths in the last century. As I mentioned at the beginning of this answer, I wrote this words only in his memory, after having discussed with him in many conferences, where he proved to be a true gentleman.

Finally, Mr. Editor, what does it happen when we face something new and unknown? What does it happen when the future opens before our feet and gives us challenges and new problems? We can fear the future, be suspicious of its progress and the responses it brings.

But we can also embrace the future, celebrate it, and investigate what opportunities it offers to us even at the risk of making mistakes and having to start again.

Like any innovative proposal, HUMA method rises comments, questions and objections. Moreover, by containing a novel paradigm and some presuppositions outside the known data, these observations need to grow and improve. But criticisms need not be born from the fear of the future, but from a genuine will to achieve together a better homeopathy.

\section{Reference:}

[1] Eizayaga J. REDIMEH Project: Ibero-American Integrative Network for Clinical Research in Homeopathy. Int J High Dilution Res. 2009; 8 (27): 50-52. Available from: http://www.feg.unesp.br/ ojs/index.php/ijhdr/article/view/340/392

\section{(c)) EY-NC-ND Licensed to GIRI}

Correspondence author: Dr. Marcelo Candegabe, marcelocandegabe@universidadcandegabe.org, www.universidadcandegabe.org.

How to cite this article: Candegabe M. Fear of the future: A response to Dr. José Eizayaga [Letter to the Editor]. Int J High Dilution Res. 2009 [cited YYYY Month dd]; 8(28): 82-87. Available from:

http://www.feg.unesp.br/ ojs/index.php/ijhdr/article/view/350/395. 